\title{
The Impact of Social Influence and Third Party Endorsement on Online Shopping in Saudi Arabia
}

\author{
Haya Alshehri and Farid Meziane \\ School of Computing, Science and Engineering \\ University of Salford, UK
}

Correspondence should be addressed to: Haya Alshehri; h.alshehri1@edu.salford.ac.uk

Received date: 15 September 2014; Accepted date: 27 January 2015; Published date: 2 September 2015

Academic Editor: Rozalia Nistor

Copyright (C) 2015. Haya Alshehri and Farid Meziane . Distributed under Creative Commons CC-BY 4.0

\begin{abstract}
It is well documented that social influence and third party endorsements play a significant role in developing trust in E-Commerce. Previous studies have shown that it is relatively true in many countries and across cultures. However, very few studies were conducted in the Middle East and to our knowledge this was the first time to consider family members and friends Recommendation with the context of social influence conducted within Saudi Arabia. The research reported in this paper attempts to investigate whether the findings from previous studies will be similar in Saudi Arabia. Specifically, this study will evaluate the impact of social influence and endorsements on online shopping and whether this plays an important role in increasing online shopping in Saudi Arabia. The results of this study are based on quantitative data collected from a sample of 606 Saudi citizens living in Saudi Arabia. Four factors connected to the impact of social influence and third party endorsements in online shopping are examined. The initial findings of this research confirm that there are similarities with the results of previous studies conducted in other countries. Similarly, the impact of social influence and third party endorsements seems to encourage and support the development of online shopping in Saudi Arabia.
\end{abstract}

Keywords: E-Commerce, Saudi Arabia, Family members and Friends Recommendation, Third Party, Quantitative Research.

\section{Introduction}

E-Commerce developed as a consequence of the information and communications technology (ICT) revolution and had a huge influence in the economic area and contributed to its growth. ICT has a huge influence on societies, businesses and shoppers (Jehangir et al., 2011). Several businesses in developing countries are in the initial phases of the implementation of ECommerce. The change of companies' strategies and success in these countries and their move to more advanced stages of ECommerce use depend on their abilities to adopt and implement these new technologies

Cite this Article as: Haya Alshehri and Farid Meziane (2015)," The Impact of Social Influence and Third Party Endorsement on Online Shopping in Saudi Arabia ", Journal of Internet and e-Business Studies, Vol. 2015 (2015), Article ID 146746, DOI: 10.5171/2015.146746 
in their commercial activities. However, many of these companies are faced with environmental and societal factors that they need first to address and overcome. Some of these factors have been identified in many studies to include the reluctance of local populations to engage in E-Commerce transactions due mainly to the lack of trust in these new technologies.

This study attempts to investigate the influence of recommendations from family members, friends and third parties in using E-Commerce in Saudi Arabia. Indeed, many societies such as the Saudi society are known to be more collectivist than individualist (Turel and Connelly, 2012) and the decision making process seems to be influenced by groups. Hofstede and Hofstede (2005) stated that there are four socio-cultural dimensions: (i) power distance index which represents "the extent to which the less powerful members of organizations and institutions (like the family) accept and expect that power is distributed unequally", (ii) uncertainty avoidance which refers to the density of societies' efforts to avoid concern, (iii) individualism/collectivism that stand for whether social performers highly appreciate the decision of the individual or the group agreement and (iv) masculinity/femininity which refer to what gender values control the societies. Hofstede and Hofstede (2005) specified that the cultural characteristics of a considerably high power distance, collectivism orientations, femininity or masculinity characteristics and high uncertainty avoidance are better describing Middle Eastern countries. In fact, Arab nations are classified as collectivist cultures where families and tribes offer protection for individuals which are born into these citizens (Hofstede and Hofstede, 2005).

In other words, we try to find out if their trust in shopping online would be enhanced when gaining the recommendations of their family members, friends and third parties. In Saudi Arabia, it has been identified that privacy, mainly the misuse of personal information, is one of the key obstacles in the growth of E-Commerce (AlGhamdi, Drew and AlFaraj, 2011). The results of such a study will help in getting a better understanding on whether the recommendations of family members, friends and third parties could affect the decision of engaging in ECommerce transactions in Saudi Arabia. The remaining of the paper is organized as follows. In section 2, a short background on E-Commerce and social recommendations, such as families, friends, and third parties influence in the engaging and use of ECommerce is given. Section 3 presents the research methodology and Section 4 summarizes the outcomes of the study.

\section{Background}

\section{E-Commerce and trust}

B2C E-Commerce is acknowledged as one of the principal accomplishments of the growth and development of the WWW. E-Commerce is seen as a revolution in the business world, since the establishment of E-Commerce as the new "dimension" that is added to the whole plan of business, as a result of smart and fast facilities (Rajon, Al-Nahid and Arif, 2011). Some large businesses are establishing a web presence and are involved in E-Commerce as an approach of raising their incomes (Laudon and Traver 2013). In fact, E-Commerce is recognized as a technique to grow sales and make profits (Shahdad and Nakhaie, 2011). E-Commerce is gaining 'competitive' values as it is allowing access to universal marketplaces and is an appropriate way for all types of companies (Jehangir et al., 2011). Consumers could buy from marketplaces worldwide without traveling to pick up the goods and/or try the services. Various clienteles have engaged in their favored shopping whether those who were from digital or nondigital services such as online tickets, music, books and cameras (Croome, Lawley, and Sharma, 2010). E-Commerce provides services that allow consumers to buy, sell and pay through the WWW and it has been fully set up and implemented in developed countries. Moreover, recommendations by family members, friends and endorsements by third parties have seen improvements in the adoption of B2C E-Commerce in the western world. However, developing nations have not gained the full benefits and advantage of E-Commerce. Several studies have confirmed that E-Commerce in developing countries will be challenged with 
more risks than in the developed ones (Molla and Licker, 2005). There are various issues that make it challenging for online firms to develop trust through consumers as compared to the tradition stores. Trust is one of the key issues that is affecting the engagement of societies in E-Commerce activities. Face-to face experience cannot be changed between purchasers and sellers and also, between buyers and goods (Araujo, 2004). Absence of trust is identified as a main issue obstructing the development of ECommerce (Meziane and Kasran, 2008). Online customers are able to search the website and trust the business, which has potential advantages to the web merchant (Araujo, 2004). It is a vital research area where researchers can study the methods by which customers interact through technology, evaluate its reliability and offer guidelines for trusting these new technologies.

\section{Social and third party recommendations}

Social recommendations outlined in this study increase online trust and are gained from family members, friends and third parties. Indeed, a sense of chaos in the ECommerce marketplace might be felt by customers; for example, they may fear that their personal information could be stolen due to untrustworthy online companies (Head, and Hassanein, 2002). It is well known that information accuracy, which is found in the E-Commerce websites, is incomplete (Meziane and Kasiran 2008). Some businesses claim to have a 'privacy policy', however there is no assurance that it can be found on the merchants' websites and the reviews that are found on many of these websites are hard to verify that they are from genuine consumers (Meziane and Kasiran 2008). Therefore, friends and family members' recommendations enhance the trust of some business websites (Nor and Pearson, 2008). Referees are third parties that deliver independent "recommendations" on the credibility of sellers and they might be derived in several ways, such as individual recommendations, media and watchdogs (Head, and Hassanein, 2002). In fact, initial trust is a very significant concern in the field of B2C EC. Trust can be increased by social and third party recommendations. Jarvenpaa et al. (1999), Jarvenpaa et al. (2000) stated that the perception of reputation of online stores by consumers impacts on their trust. Relatives, colleagues and friends are able to influence the individual to form initial acceptance decisions of online practices (Parthasarathy and Bhattacherjee, 1998; Limayem, Lhalifa, and Frini, 2000). It has been found that recommendations from friends or family members enhance engagement in EC activities through mobile phone (Hillman, Neustaedter, Bowes, and Antle, 2012). Engagement in a mCommerce activity, straight from social media platform recommendations, increases shopping online based on the influence of friends' recommendations (Hillman, et al., 2012). Social recommendations by families and friends have an effective impact to buy and/or not to buy via the Internet market for the reason that the quality of goods and serveries can be confirmed. It has been found that "recommendations by close friends and families are known as an influencing factor on reputation" which affect positively on ECommerce trust (Meskaran, Abdullah, and Ghazali, 2010). Sinha and Swearingen (2001) stated that users can continuously gain better recommendations than other recommender systems by their friends. Also, recommendations of a merchant reputation are greatly better than most other recommendation systems (Swearingen and Sinha, 2001). It is accepted that recommendations by family members and friends are an important aspect in developing online shopping trust.

\section{Research Methodology}

This study used a survey method to examine Saudis' attitudes towards recommendation by family members and friends when they engage in online shopping in Saudi Arabia. This method enabled us to carry out an experiential investigation of phenomenon in its real life environment where they have strong relationships with their families and friends. In this part of the research, questionnaires were used and validated by a pilot study. The questionnaire was designed in English and then translated into the Arabic Language. The Likert scale of 1-5 where 1 was "strongly disagree" and 5 was "strongly agree" was used. 
The outcomes presented in this paper are part of a larger study which is trying to develop a framework of B2C E-Commerce in Saudi Arabia. The part of the questionnaire dealing with the effect of recommendation by a family member and friends to support ECommerce acceptance is given in Table 1.

Table 1: The recommendation by a family member and friends' part of the questionnaire

\begin{tabular}{|l|l|c|c|c|c|}
\hline $\begin{array}{l}\text { To what extend do you agree or disagree with the following statements that relate to recommendation by } \\
\text { family members and friends? }\end{array}$ & $\begin{array}{l}\text { Strongly } \\
\text { Disagree }\end{array}$ & Disagree & Neutral & Agree & $\begin{array}{l}\text { Strongly } \\
\text { Agree }\end{array}$ \\
\hline $\begin{array}{l}\text { I will buy from a company that is } \\
\text { recommended by a member of my family }\end{array}$ & 1 & 2 & 3 & 4 & 5 \\
\hline $\begin{array}{l}\text { I will buy from a company that is } \\
\text { recommended by a friend. }\end{array}$ & 1 & 2 & 3 & 4 & 5 \\
\hline $\begin{array}{l}\text { I will buy online if the company is a } \\
\text { member of a well known group of } \\
\text { companies }\end{array}$ & 1 & 2 & 3 & 4 & 5 \\
\hline $\begin{array}{l}\text { I will buy online if I the company is } \\
\text { endorsed by a third party }\end{array}$ & 1 & 2 & 3 & 4 & 5 \\
\hline
\end{tabular}

The sample used is composed of 606

respondents. The distribution of the sample

with regards to gender is given in Table 2 .

Table 2: Gender and Age distribution of the sample

\begin{tabular}{|l|l|l|}
\hline \multirow{2}{*}{ Gender } & Male & 213 \\
\cline { 2 - 3 } & Female & 393 \\
\hline Total & 606 \\
\hline
\end{tabular}

\section{Results}

There must be a reliable and valid measurement tool to evaluate the results of this study. It is significant that the research based on measurement can deliver the validity, that shows the extent to which this instrument is able to measure whether the questions are well designed to gain the estimated answers (Oates, 2006). Cronbach's
Alpha is the most communally used test for measuring scale reliability (Field 2005). The number of participants in the sample is 606 from the Saudi general population. The Cronbach's Alpha obtained is .757 and this is summarized in Table 3. As shown, the reliability is high as according to Hinton et al., (2004) reliability in the range (0.70-0.90) is considered to be high.

Table 3: Reliability Statistics, Cronbach's Alpha

\begin{tabular}{|l|l|l|}
\hline Cronbach's Alpha & Cronbach's Alpha Based on Standardized Items & No of Items \\
\hline .795 & .801 & 4 \\
\hline
\end{tabular}

The aim of this part of the study is to find out if there are effective aspects that enhance Saudi online buyers when they gain recommendation from a family member and friends regarding their experience in buying online.
The first part of the study looks at the willingness of the participants to buy if they are being recommended by a family member. The second part is to find out if they will buy from a company that is recommended by a friend. The third part attempts to understand if participants will buy online if the company 
is a member of a well known group of companies. The final part tries to understand if they will buy from a company that is endorsed by a third party.

On the question of whether they will buy online if the company is endorsed by a third party, Figure 1 shows the summary of the responses. Around 34.7\% agree that they will buy online if a company is recognised by a third party and around $22.4 \%$ strongly agree. About $32.7 \%$ are not definite about their opinion therefore their answer was neutral. Close to $10 \%$ disagree or strongly disagree.

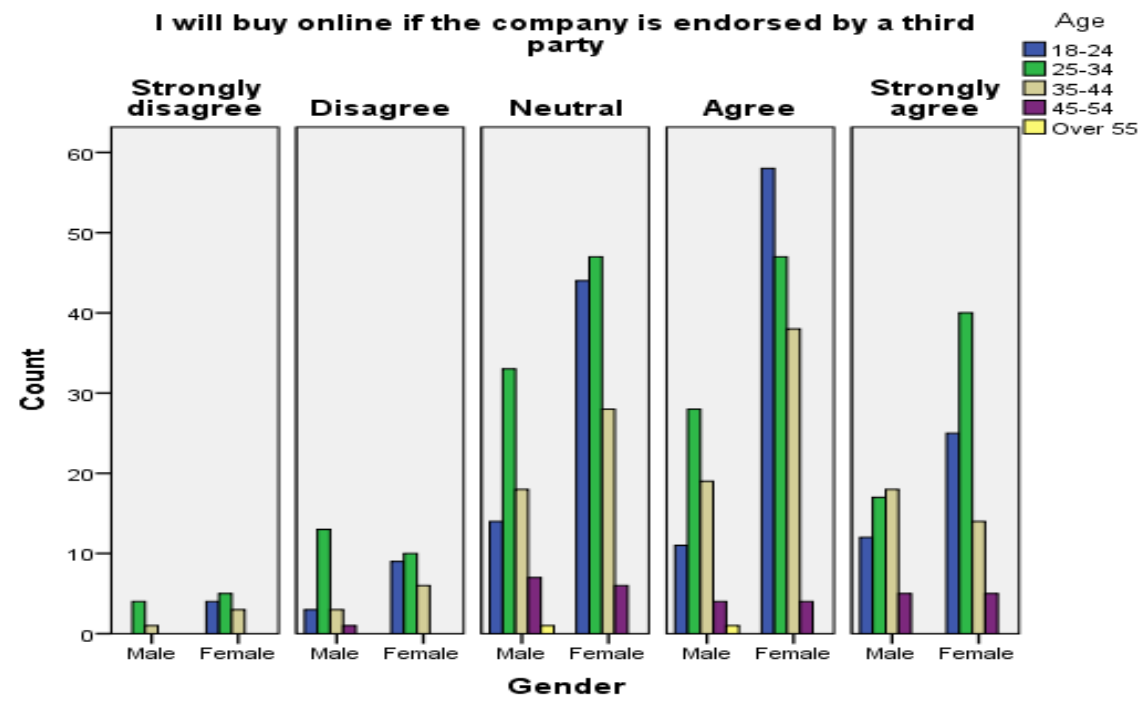

Figure 1: I will buy online if the company is endorsed by a third party

Figure 2 shows the results of the survey with regards to whether participants will buy online if the company is a member of a well-known group of companies. Around $47 \%$ agree that they will buy online if the company is a member of a well-known group of companies and around $36.3 \%$ strongly agree. The percentages of participants that disagree or strongly disagree represent around $2.8 \%$.

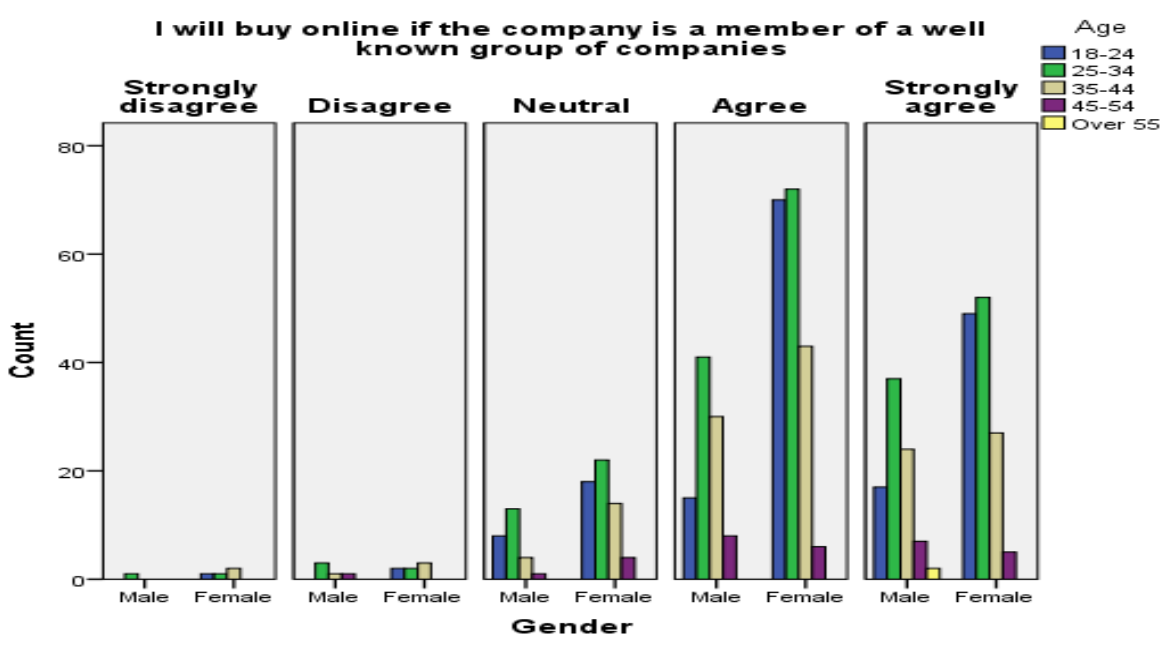

Figure 2: I will buy online if the company is a member of a well-known group of companies 
With regards to buying online from a company that is recommended by a friend, Figure 3 summarises the results of this study. Around $48 \%$ agree that they will buy online from a company that is recommended by a friend and around 26\% strongly agree. Around 5\% disagree or strongly disagree.

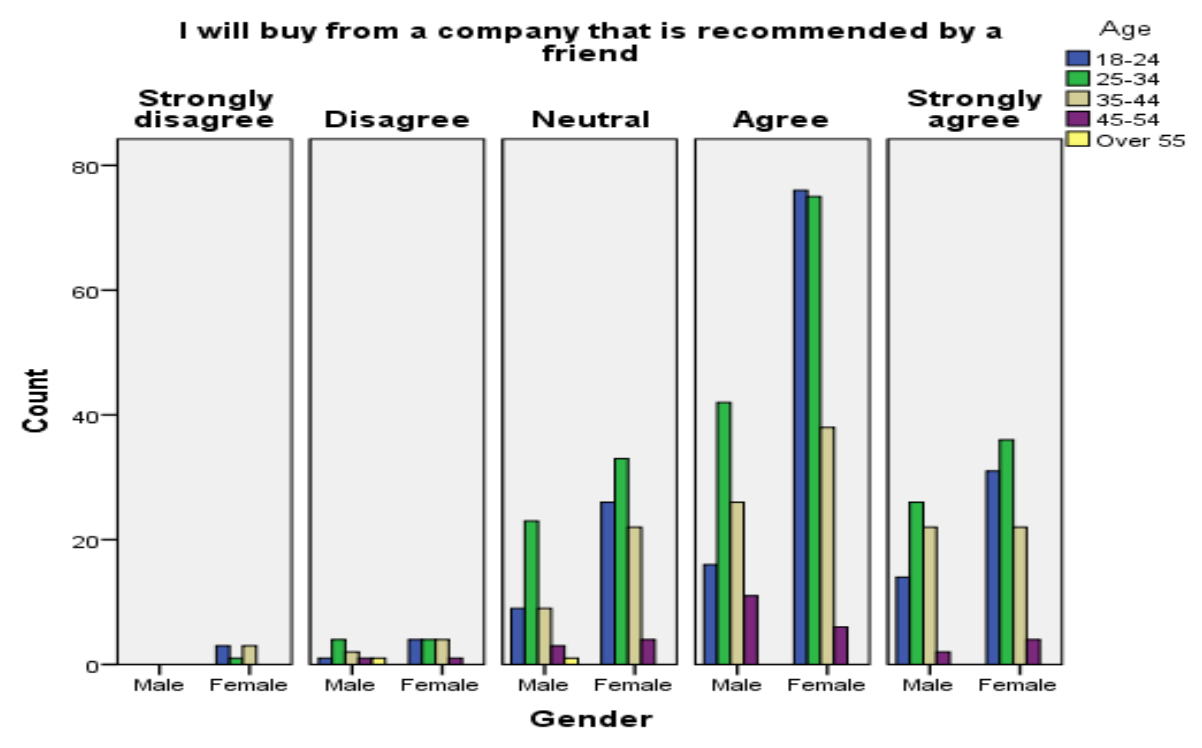

Figure 3: I will buy from a company that is recommended by a friend

Figure 4 illustrates the results with regards to participants who will buy online from companies that are recommended by a family member. Around $52 \%$ agree and around $30 \%$ strongly agree. There are around $4 \%$ that disagree or strongly disagree.

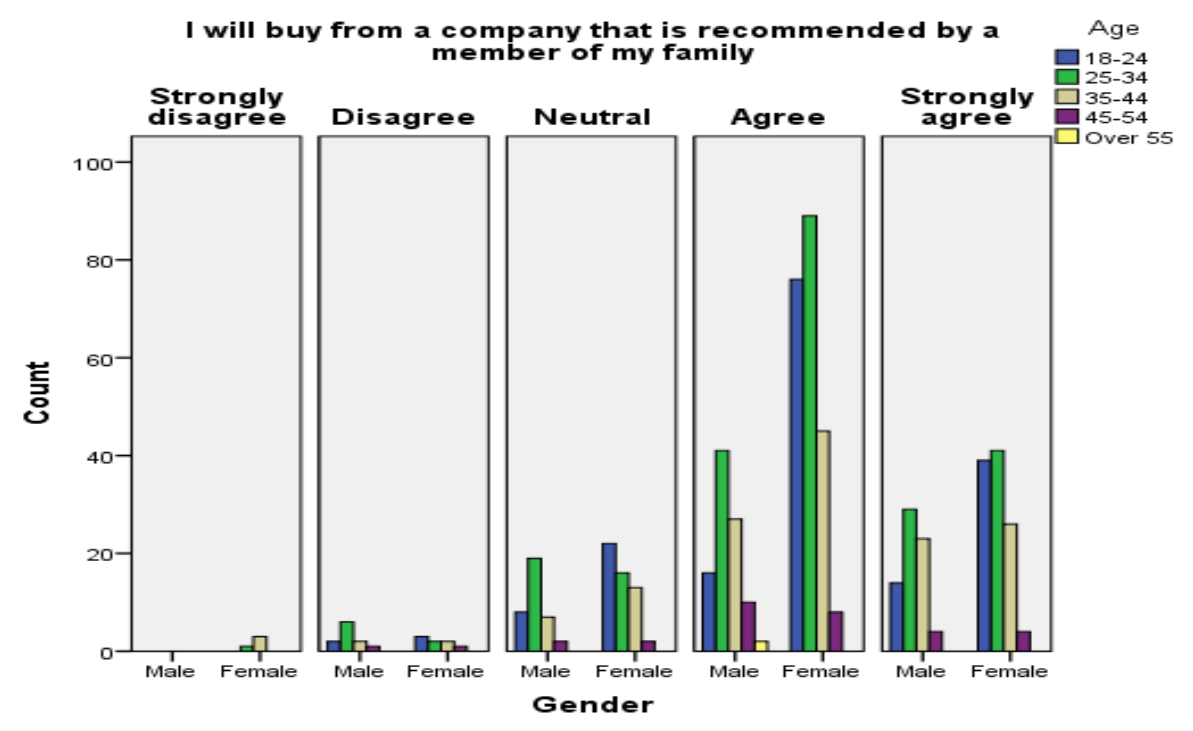

Figure 4: I will buy from a company that is recommended by a member of my family. 


\section{Conclusion}

This research contributes to B2C ECommerce field by presenting a new scope to improve wide knowledge of customer behaviors. Besides, confirming constructs' influences perceptions toward trusting the recommendations of families, friends and third party endorsement within the context of Saudi Arabia. This research may help in providing a better understanding and more visions about the factors affecting online trust in E-Commerce. This study investigated Saudis' attitudes towards engaging in B2C ECommerce based on the recommendations by family members, friends and endorsed by a third party when they engage in online transactions.

The outcomes of this study were summarized in the previous sections. A light analysis of these initial results illustrates that in general, Saudis seem to be more comfortable and/or trust more when they gain recommendations by a family member, friends and endorsement by a third party when shopping online.
It is of value to note that a member of a wellknown group of companies is a strong and effective factor which enhances participants to trust buying online (83.3\%). There are also $81.5 \%$ of the respondents that trust their family members' recommendations, and around $73.8 \%$ for those who also will accept and trust recommendations from friends. More than half of respondents are fine with endorsements by a third party, which is a supportive factor that enhances them to buy online $(57.1 \%)$.

In fact, when moving toward very specific information a big number of respondents are affected by trust in the recommendations of a member of family and/or friend, therefore this demonstrates the strength of family and social relationships.

The level of customer trust will increase if a company is endorsed by a third party and is a member of a well-known corporation since that will reduce the fear of the risks that accompany shopping online.

The results are summarized in Table 4.

Table 4: Summary of the respondents for individual information

\begin{tabular}{|l|l|l|l|l|}
\hline $\begin{array}{l}\text { Company } \\
\text { which }\end{array}$ & $\begin{array}{l}\text { Endorsed by } \\
\text { a third party }\end{array}$ & $\begin{array}{c}\text { Member of a well } \\
\text { know group of } \\
\text { companies }\end{array}$ & $\begin{array}{c}\text { Recommended } \\
\text { by a friend }\end{array}$ & $\begin{array}{c}\text { Recommended by a } \\
\text { member of my } \\
\text { family }\end{array}$ \\
\hline $\begin{array}{l}\text { Agree/S. } \\
\text { Agree }\end{array}$ & $57.1 \%$ & $83.3 \%$ & $73.8 \%$ & $81.5 \%$ \\
\hline $\begin{array}{l}\text { Disagree/S. } \\
\text { Disagree }\end{array}$ & $10.2 \%$ & $2.8 \%$ & $4.8 \%$ & $3.8 \%$ \\
\hline
\end{tabular}

Extra statistical analyses on the sample are required to obtain more detailed understanding of the behaviour of the participants. Tests should be achieved to approve or not the significance of the answers based on gender and age groups.

As a final point, this outcome aspect would provide several benefits to the Saudi online sales development which perhaps can enhance the national economy growth to similar countries' environment growth.

\section{Acknowledgment}

This paper was financed by the Ministry of higher education in Saudi Arabia, I would like to express thanks for supporting this work, and I wish to thank the Saudi Arabian Cultural Bureau in London for their continuous backing.

\section{References}

1. AlGhamdi, R., Drew, S., \& AlFaraj, 0. (2011). 'Issues Influencing Saudi Customers' Decisions to Purchase from Online Retailers in the KSA: A Qualitative Analysis' European 
Journal of Scientific Research, 55 (4), 580593.

2. Araujo, I. (2004), 'Establishing longTerm trust in e-commerce' International Conference on e-Commerce (IADIS), 14-16 December 2004, Lisbon, Portugal, 422-429.

3. Croome, R., Lawley, M., Sharma, B. (2010), 'Antecedents of Purchase in the Online Buying Process', Journal of Internet Business, (8), 1-40.

4. Field, A. P. (2005) Discovering Statistics Using SPSS, $2^{\text {nd }}$ edition, Sage, London.

5. Head. M., and Hassanein, K. (2002), 'Trust in e-Commerce: Evaluating the Impact of Third Party Seals', Quarterly Journal of Electronic Commerce, 3 (3), 307-325.

6. Hinton, P. R., Brownlow, C., McMurray, I. and Cozens, B. (2004) SPSS Explained, Routledge Inc., East Sussex, England.

7. Hillman, S. Neustaedter, C. Bowes, J. and Antle, A. (2012), 'Soft Trust and mCommerce Shopping Behaviours. MobileHCI '12 Proceedings of the $14^{\text {th }}$ international conference on Human-computer interaction with mobile devices and services', San 21-24 December 2012, Francisco, CA, USA, 113-122

8. Hofstede, G. and Hofstede, Gert-J. (2005), Cultures and Organizations: Software of the Mind, McGraw-Hill Education, New York.

9. Jarvenpaa, S. L., Tractinsky, N., Saarinen, L., (1999), 'Consumer Trust in an Internet Store: Cross-Cultural Validation', Journal of Computer Mediated Communications, 5, 2.

10. Jarvenpaa, S. L., Tractinsky, J., and Vitale, M. (2000). Consumer trust in an internet store. Information Technology and Management, 1, pp. 45-71.

11. Jehangir M., Dominic P.D.D, Naseebullah and Khan, A. (2011), Towards Digital Economy: The Development of ICT and ECommerce in Malaysia. Modern Applied Science, 5(2):171-178.
12. Laudon, K.C. and Traver C.G.(2013), Ecommerce: Business, Technology, Society ( $9^{\text {th }}$ Edition), Pearson Prentice Hall, New Jersey.

13. Limayem, M. Lhalifa, M. and Frini, A. (2000), 'What Makes Consumers Buy from the Internet? A longitudinal Study of Inline Shopping' IEEE transactions on Systems, Man and Cybernetics-Part A: Systems and Humans, 30 (4), 421-432.

14. Meskaran, F., Abdullah, R., and Ghazali, M. (2010), 'A conceptual Framework of Iranian Consumer Trust in B2C Electronic Commerce', Computer and Information Science 3 (2), 126-139.

15. Meziane, F. and Kasiran, K. (2008), 'Evaluating Trust in Electronic Commerce: A Study Based on the Information Provided on Merchants Websites', Journal of the Operational Research Society, 59 (4), 464472.

16. Molla A. and Licker P.S. (2005), 'Perceived e-readiness Factors in EC Adoption: an Empirical Investigation in a Developing Country', International Journal of Electronic Commerce, 10 (1), 83-110.

17. Nor, K. M. and J. M. Pearson, J. M. (2008), 'An Exploratory Study into the Adoption of Internet Banking in a Developing Country', Malaysia, Journal of Internet Commerce, The Haworth Press, 7(1), 29-73.

18. Oates, B. J. (2006) Researching Information Systems and Computing. London.

19. Parthasarathy, M. and Bhattacherjee, A. (1998), 'Understanding Post-adoption Behavior in the Context of Online Services', Information Systems Research, 9 (4), 362-79.

20. Rajon, S. A. A., Abdullah-Al-Nahid and Arif, A. S. M. (2011), 'A Generic Framework for Implementing Electronic Commerce in Developing Countries', International Journal of Computer and Information technology (IJCIT), 01(02),42-53.

21. Sinha, R. and Swearingen, K. (2001), Comparing Recommendations Made by Online Systems and Friends, In Proceedings of 
the DELOS-NSF Workshop on Personalization and Recommender Systems in Digital Libraries.

22. Shahdad Nejad, N. and Nakhaie, $H$. (2011), 'The Role of Culture in the Development of Electronic Commerce', 3rd International Conference on Information and Financial Engineering, Singapore, 12, 513517.
23. Swearingen, K. and R. Sinha. (2001). Beyond algorithms: An HCI perspective on recommender systems, Workshop on Recommender Systems, New Orleans.

24. Turel, O. and Connelly, C. E. (2012). Team Spirit: The Influence of Psychology Collectivism on the Usage of E-Collaboration Tools. Group Decision and Negotiation, 21, 703-725. 